\title{
Reducing Dynamic Loads of Mining Machinery Electric Drive at Starting
}

\author{
Eshchin Evgeny $\mathrm{K}^{\mathrm{a}}$, Sokolov Igor $\mathrm{A}^{\mathrm{b}}$ \\ T. F. Gorbachev Kuzbass State Technical University, \\ Kemerovo, Russian Federation. \\ aeke_kuzstu@mail.ru, bskelvin@mail.ru
}

\begin{abstract}
The issue of the squirrel-cage induction motor start-up mode control is considered. Its unsatisfactory dynamic state in the direct power connection mode is remarked. The problem of the squirrel-cage induction motor start-up mode control based on the definition of its current electromagnetic state, while selecting either supply voltage amplitude or additional stator circuit resistance value as the control actions, is formulated. On the basis of the maximum principle of L.S. Pontryagin and sufficient conditions for the absolute minimum of V.F. Krotov, the necessary changes in the supply voltage amplitude and the stator circuit resistance, providing the practice-orientated electromagnetic torque ripple elimination, are established. The operation results of the induction motor simulation model demonstrating the good quality of the start-up transient by proposed methods are shown.
\end{abstract}

Keywords - induction motor, start-up, control, electromagnetic moment, voltage amplitude, stator circuit re-sistance.

\section{INTRODUCTION}

The widespread use of squirrel-cage induction motor is ubiquitous for the coal mining industry. This range of electric machines demonstrates the exceptional reliability, the high overload capability and the ease of operation for many years.

However, this motor has a deficient start-up dynamic performance. High multiplicities and electromagnetic torque ripples in this mode have a negative impact on the state of the electric motor itself as well as its mechanical system.

There are ways to describe, for example [1,2,3], and eliminate the negative processes that accompany the squirrelcage induction motor start-up process, for example [4-8].

The main known methods of improving the dynamic state of the induction motor by reducing the starting voltage magnitude supplied to the motor $[9 \div 15]$ :

- the stator winding reconnection from star to delta (stardelta);

- the use of autotransformers (autotransformer);

- the connection of additional resistances to the stator circuit of the induction motor (Primary Resistor);
- the use of rectifier-based soft-starter techniques (SoftStarter Techniques).

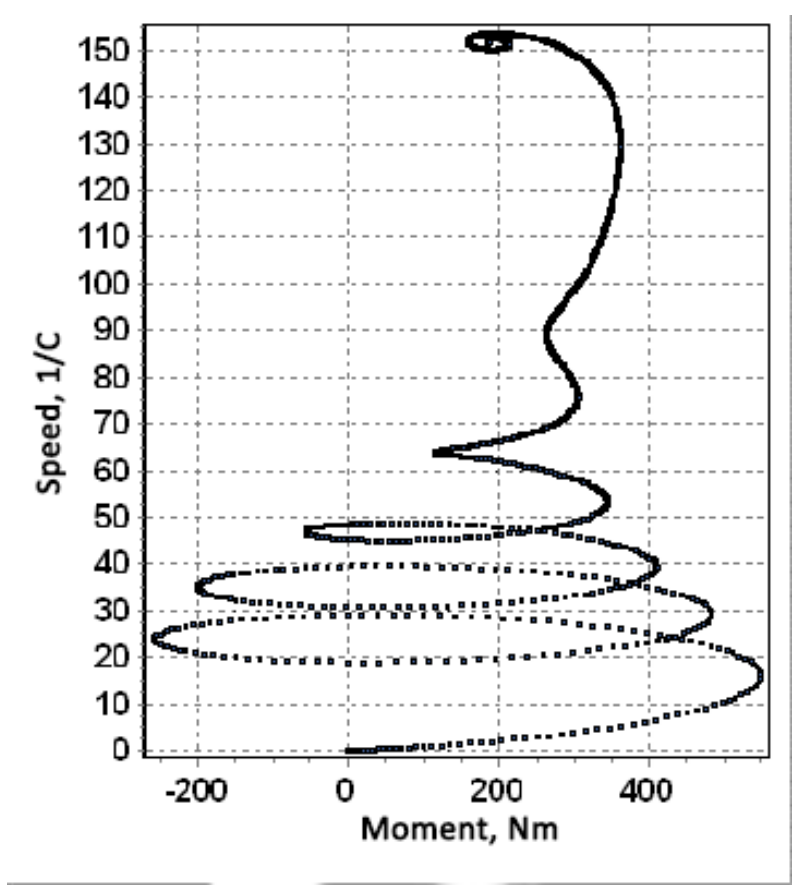

Fig. 1. The example of the typical form of the deficient dynamical mechanical performance

It should be noted that these methods of forming the starting characteristics of the induction motor are intuitive, for asynchronous motor control algorithms implemented by them are simple and use, as a rule, the rotor speed or the current value of the stator current to assess its condition. The assessment of current (instantaneous) values of electromagnetic state parameters (flux linkages) of induction motor is not performed. Some of them have conditionally complex induction motor control systems and are not always acceptable in terms of mining production.

So the development of methods for the induction motor start-up mode control possessing both the required efficiency to ensure the control quality (elimination of the start-up 
dynamic phenomena), and the implementation ease of this operation mode control system is urgent.

In this context, the task of the research is the development of analytical structures of the induction motor start-up mode control system based on the assessment of its current electromagnetic state while selecting either supply voltage amplitude (for star-delta, autotransformer and soft-starter techniques options) or additional stator circuit resistance value (primary resistor option) as the control actions. The basis for the solution search may be, for example, the maximum principle of L.S. Pontryagin, sufficient conditions for the absolute minimum of V.F. Krotov [16,17].

\section{MATERIALS AND METHODS}

Let's consider the problem of the optimal control of the induction motor start-up using a maximum principle of L.S. Pontryagin. The purpose of the control is to provide the proximity of induction motor electromagnetic torque and moment determined by its static mechanical characteristics given by, for example, the revised formula of Kloss. Control action is the induction motor supply voltage amplitude (stardelta, autotransformer, soft-starter techniques). Let's indicate this control option as Control_U.

Analytically the control objective is written in the form of functional

$$
J=\inf \left(\int_{0}^{t}\left(M_{n}-M\right)^{2} d t\right)
$$

where $M_{n}, \quad M$ is the necessary and the current electromagnetic torque value of the induction motor.

$$
\begin{aligned}
& \left.\frac{d \Psi_{s u}}{d t}=U_{s u}-\frac{R_{s}}{L_{s}^{\prime}} \Psi_{s u}+\frac{R_{s}}{L_{s}^{\prime}} k_{r} \Psi_{r u}+\omega_{n} \Psi_{s v}=\quad f[6]\right) \\
& \frac{d \Psi_{s v}}{d t}=U_{s v}-\frac{R_{s}}{L_{s}^{\prime}} \Psi_{s v}+\frac{R_{s}}{L_{s}^{\prime}} k_{r} \Psi_{r v}-\omega_{n} \Psi_{s u}=\quad f[7], \\
& \left.\frac{d \Psi_{r u}}{d t}=-\frac{R_{r}}{L_{r}^{\prime}} \Psi_{r u}+\frac{R_{r}}{L_{r}^{\prime}} k_{s} \Psi_{s u}+\left(\omega_{n}-p \omega\right) \Psi_{r v}=f[8],\right\}(1) \\
& \frac{d \Psi_{r v}}{d t}=-\frac{R_{r}}{L_{r}^{\prime}} \Psi_{r v}+\frac{R_{r}}{L_{r}^{\prime}} k_{s} \Psi_{s v}-\left(\omega_{n}-p \omega\right) \Psi_{r u}=f[9], \\
& \frac{d \omega}{d t}=J^{-1}\left(c\left(\Psi_{r u} \Psi_{s v}-\Psi_{s u} \Psi_{r v}\right)-M_{c}\right)=
\end{aligned}
$$

The equations of the induction motor motion is defined by [1.2]: here the parameters that begin with $R$ and the indices $s, r$ are the induction motor stator and rotor winding resistance; $L_{s}^{\prime}, L_{r}^{\prime}$ are the transient inductance of the stator and the rotor; $k_{r}, k_{s}$ - are the electromagnetic coupling coefficients; $p$-is the number of pole pairs, $\omega_{n}-$ is the electrical stator field rotation rate; $\omega$ - is the geometric angular rotor rotation rate; $\Psi_{s} \Psi_{r}$, with the indices $u, v$ - are components of the stator and the rotor flux linkages for each axis of the synchronous coordinate system; $U_{s}$ - with the coordinate system indices - are the components of the stator and the rotor voltage (control actions); $J$ - moment of inertia; $f[6] \div f[10]$ - are the right hand side of the motion equations.
$H$ function of the maximum principle and the system for determining the auxiliary variables $\Psi_{i}$ (included in $H$ ) can be written as:

$$
\begin{aligned}
& H=\sum_{i=1}^{5} \Psi_{i} f[i+5]+\Psi_{0} f_{0}, \\
& \dot{\Psi}_{i}=-\frac{\partial H}{\partial x^{i}}=f[i], \quad i \in(1 . .5)
\end{aligned}
$$

Here $x^{i}$ is in sequence $-\Psi_{s u}, \Psi_{s v}, \Psi_{r u}, \Psi_{r v}, \omega$,

$$
f_{0}=\left(M_{n}-M\right)^{2} \div \Delta M^{2} \text {. }
$$

It should be noted that the solution of the optimal control problem is made not in the classical form, when the analytical design of the synthesis function is sought, but by direct numerical solution of the set of differential induction motor movement equations (1), the system of differential equations for the definition of the auxiliary variables $\Psi_{i}$ and use the properties of the auxiliary function $(H \equiv 0)$ in optimum conditions. The algorithm for generating the stator winding voltages (Control_U) is simple (Figure 2). The result of the introduction of such a voltage control is Figure 3.

Let us consider in detail one more opportunity to actively influence on the induction motor start-up process. Namely, by the change of the total stator circuit resistance value i.e. Primary Resistor option. Let's indicate this control option as Control_R.

The induction motor state will be also described by the system of differential constraints (1), defining the nature of the change of phase coordinates with allocation and the definition of the control action $-R_{s}$.

The solution can be obtained on the basis of sufficient conditions for the absolute minimum [17]. This requires the formation of an auxiliary function:

$$
\begin{aligned}
& R\left(\Psi_{s}, \Psi_{r}, R_{s}, t\right)==\frac{\partial \varphi}{\partial \Psi_{s u}} f[6]+\frac{\partial \varphi}{\partial \Psi_{s v}} f[7]+ \\
& +\frac{\partial \varphi}{\partial \Psi_{r u}} f[8]+\frac{\partial \varphi}{\partial \Psi_{r v}} f[9]-\left(M_{n}-M\right)^{2}+\frac{\partial \varphi}{\partial t}
\end{aligned}
$$

where $\varphi=\varphi\left(t, \Psi_{S}, \Psi_{r}\right)$ - is an arbitrary function of the phase coordinates and the time.

For the moving boundary problems, which include the considered problem, the absolute extremum condition can be written as:

$$
\begin{gathered}
\sup R\left(\Psi_{s}, \Psi_{r}, R_{s}\right) \equiv 0, \\
\forall\left(R_{s}\right) \in A
\end{gathered}
$$

where $A$ - the tolerance region of the equations $R_{s}$.

Since the optimal control problem is considered to be solved mathematically, if the control is found in functional form of the object (induction motor) state parameters, we 
require the temporary independence of $\varphi$, i.e., let us assume that $\partial \varphi / \partial t=0$.

Besides, the necessary conditions of the maximum $R\left(\Psi_{s}, \Psi_{r}, R_{S}, t\right)$ are the requirements -

1. $\frac{\partial R\left(\Psi_{s}, \Psi_{r}, R_{s}, t\right)}{\partial R_{s}}=0, \quad 2 . \frac{\partial R\left(\Psi_{s}, \Psi_{r}, R_{s}, t\right)}{\partial U_{r u}}=0$,

3. $\frac{\partial R\left(\Psi_{s}, \Psi_{r}, R_{s}, t\right)}{\partial U_{r v}}=0, \quad 4 . \frac{\partial R\left(\Psi_{s}, \Psi_{r}, R_{s}, t\right)}{\partial \Psi_{s u}}=0$,

5. $\frac{\partial R\left(\Psi_{s}, \Psi_{r}, R_{s}, t\right)}{\partial \Psi_{s v}}=0, \quad 6 . \frac{\partial R\left(\Psi_{s}, \Psi_{r}, R_{s}, t\right)}{\partial \Psi_{r u}}=0$,

7. $\frac{\partial R\left(\Psi_{s}, \Psi_{r}, R_{s}, t\right)}{\partial \Psi_{r v}}=0$

From the 2-nd and 3-rd relations of the former collection of differential constraints follows: $\frac{\partial \varphi}{\partial \Psi_{r u}}=0, \frac{\partial \varphi}{\partial \Psi_{r v}}=0$,

$R\left(\Psi_{s}, \Psi_{r}, R_{s}, t\right)=\frac{\partial \varphi}{\partial \Psi_{s u}}\left(U_{s u}-\frac{R_{s}}{L_{s}^{\prime}} \Psi_{s u}+\frac{R_{s}}{L_{s}^{\prime}} k_{r} \Psi_{r u}+\omega_{n} \Psi_{s v}\right)+$ $+\frac{\partial \varphi}{\partial \Psi_{s v}}\left(U_{s v}-\frac{R_{s}}{L_{s}^{\prime}} \Psi_{s v}+\frac{R_{s}}{L_{s}^{\prime}} k_{r} \Psi_{r v}-\omega_{n} \Psi_{s u}\right)-\left(M_{n}-M\right)^{2}$.

that reduces the analytical construction

From the $6^{\text {th }}$ requirement (2) we see that:

$$
\begin{aligned}
& \frac{\partial}{\partial \Psi_{r u}} R\left(\Psi_{s}, \Psi_{r}, R_{s}, t\right)==\frac{\partial^{2} \varphi}{\partial \Psi_{s u} \partial \Psi_{r u}} \times \\
& \times\left(U_{s u}-\frac{R_{S}}{L_{s}^{\prime}} \Psi_{s u}+\frac{R_{S}}{L_{s}^{\prime}} k_{r} \Psi_{r u}+\omega_{n} \Psi_{s v}\right)+ \\
& +\frac{\partial \varphi}{\partial \Psi_{s u}} \frac{R_{s}}{L_{s}^{\prime}} k_{r}+\frac{\partial^{2} \varphi}{\partial \Psi_{s v} \partial \Psi_{r u}} \times \\
& \times\left(U_{s v}-\frac{R_{S}}{L_{s}^{\prime}} \Psi_{s v}+\frac{R_{S}}{L_{s}^{\prime}} k_{r} \Psi_{r v}-\omega_{n} \Psi_{s u}\right)- \\
& -\frac{\partial}{\partial \Psi_{r u}}\left(M_{n}-M\right)^{2}=0 \text {. }
\end{aligned}
$$

It follows that: $\frac{\partial \varphi}{\partial \Psi_{s u}}=\frac{3 p}{R_{s}}\left(M_{n}-M\right) \Psi_{s v}$.

Similarly: $\frac{\partial \varphi}{\partial \Psi_{s v}}=-\frac{3 p}{R_{s}}\left(M_{n}-M\right) \Psi_{s u}$.

The use of these expressions in the auxiliary function $R\left(\Psi_{s}, \Psi_{r}, R_{s}, t\right)$ defines a rule of formation of the total stator circuit resistance value when starting the induction motor -

$$
R_{s}=3 p \frac{\left(U_{s u} \Psi_{s v}-U_{s v} \Psi_{s u}+\omega_{n} \Psi^{2}{ }_{s}\right)}{\left(M_{n}+M\right)} .
$$

\section{RESULTS}

The solution for the Control_U start-up control mode can be represented (as an option) in graphical form (Figure 2), which is easy to implement analytically.

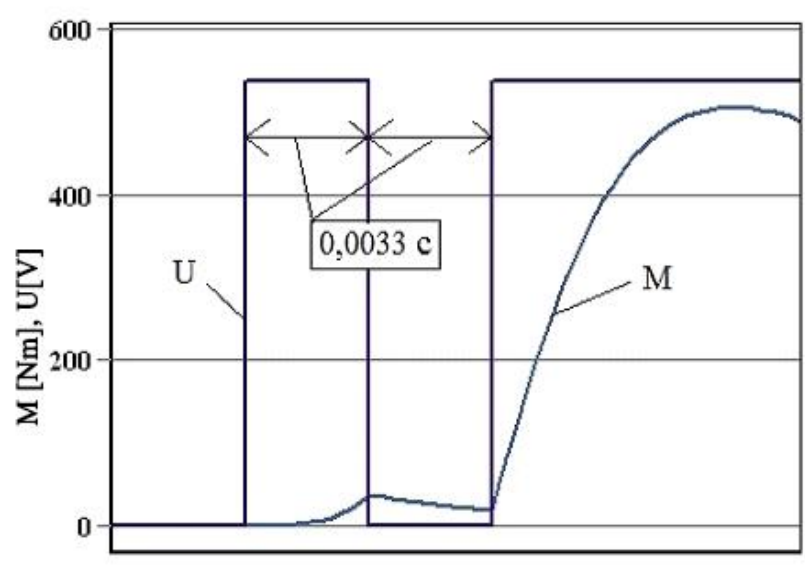

Time $[c]$

Fig. 2. The character of changes in the induction motor (U) supply voltage and the electromagnetic torque amplitudes (M) (Control_U)

The solution is the voltage pre-supply in the form of the 0.0033 seconds pulse on-time (at a supply voltage frequency of $50 \mathrm{~Hz}$ ), the subsequent transition to the magnetic braking mode for the same time and the subsequent voltage re-supply [18]. The result of this start-up control mode is Figure 3.

The implementation of the start-up control mode by connecting the additional resistances to the stator circuit (Control_R) and its change according to (3) when Mn is given by the revised formula of Kloss [19] is in Figures 4, 5.

Thus, the analytical structure (3) is the required end result, which determines the practical elimination of electromagnetic torque ripples (Figure 1) of the induction motor start-up at the expense of the short-term (in the example $\approx 0.025$ seconds) introduction of additional stator circuit resistance multiple of $\approx$ 6 of the nominal values in stator circuit (Control_R). 


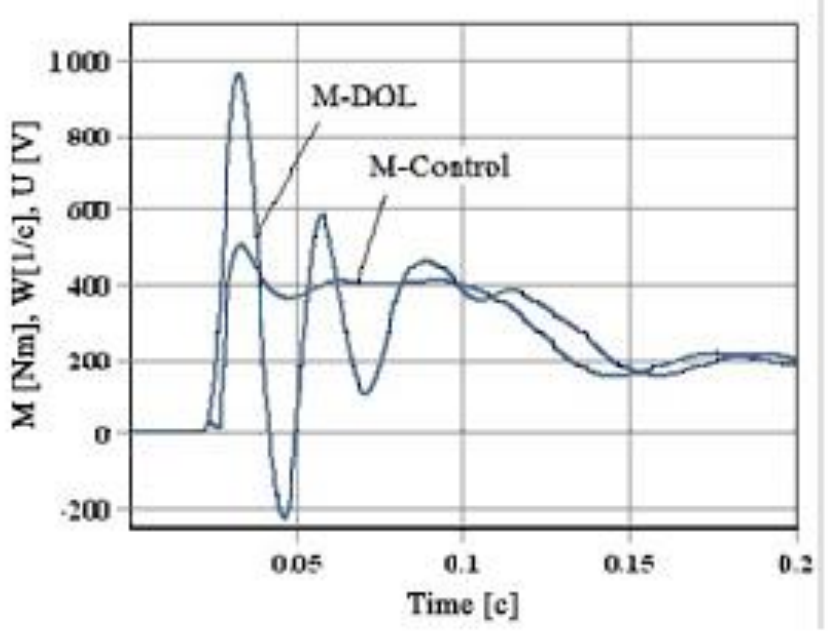

Fig. 3. The result of introduction of the the induction motor start-up supply voltage amplitude control. M-Control - the electromagnetic torque change in the formation of $U$ according to Figure 2. M-DOL - the electromagnetic torque change in direct on-line (DOL) induction motor startup

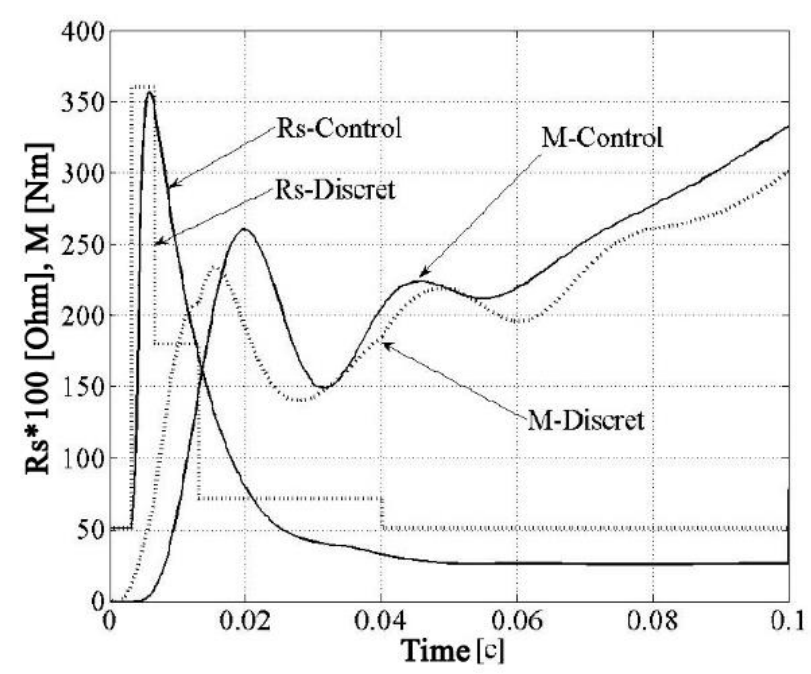

Fig. 4. The character of the electromagnetic torque changes in the induction motor (M-Control, M-Discret) under continuous (Rs-Control) and discrete (Rs-Discret) stator circuit resistance changes

\section{DISCUSSION}

Figure 1 shows the most unfavorable (the most common) direct on-line (DOL) start-up of the squirrel-cage induction motor. The start-up is carried out by a so-called no-load mode when the rotor resistance torque is almost minimal. However, despite the minimum load, and as a consequence a rapid acceleration of the rotor to the rated speed, there is the undesirable impact on the mechanical elements of the mining machine due to the shocks in the transmission.

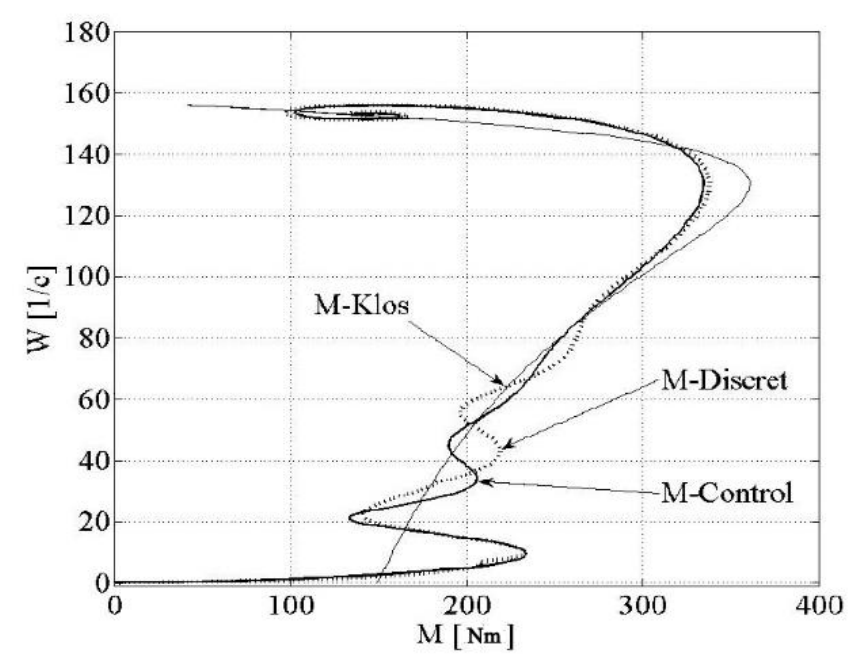

Fig. 5. The natural (M-Klos) and dynamical (M-Discret, MControl) mechanical start-up performance of the induction motor ВРП160S4 when changing the total stator circuit resistance magnitude

The sudden changes in the electromagnetic torque (5-7fold of the rated with the opportunity of partial operation in generator mode), carried out in a loop with very high, for the mechanical processes, frequency lead to the very rapid reduction of the mining machinery life.

Even more undesired mode occurs when the start-up of squirrel-cage induction motor takes place in a technological emergency situation, for example, starting the drag conveyer with the filled flight.

The introduction of the start-up mode control eliminates the electromagnetic torque ripple. Naturally, the nature of the change in the supply voltage amplitude in Control_U version is due to the limitations of the control action value (the supply voltage amplitude), which was defined as $U_{\max } \geq U \geq 0$ (Figure 2). In a more general case it is possible to extend the range of the voltage amplitude and write it in the form of $U_{\max } \geq U \geq U_{\min }$. Naturally in this case that $U_{\min }$ can take the negative values, which correspond to the induction motor operation in opposite connection mode.

When using Control_R operating option, the attention should be paid to the possibility of replacing the continuous function (3) with its discrete approximation (Rs-Discret in Figure 4). Wherein the control quality is practically not changed (Figure 5), but the practical implementation is significantly simplified.

In addition, the practical realization of the start-up devices (for controlling the voltage amplitude or the stator circuit resistance value) gives the opportunity to the sensorless applications (sensorless), which greatly simplifies the physical structure of the induction motor starters. 


\section{CONCLUSIONS}

The existing methods for the induction motor start-up only partly solve the problem of dynamic shocks acting on the mining machine during its start-up.

The construction of minimal complexity systems of induction motor start-up mode control (Control_U, Control_R), allowing starting the induction motor with the given transition process quality in order to reduce the dynamic loads to the drive.

The dynamic component of the electromagnetic torque is practically absent when the following options are used:

- Control_U - direct on-line (DOL) start-up for the duration of $0.0033 \mathrm{~s}$; ; with subsequent transition to the magnetic braking mode for the same time and the subsequent direct on-line (DOL) re-starting;

- Control_R - connection of the additional resistances in series to the primary winding of the motor. The resistance value (the behavior) can be determined according to (3), as well as to be given in a discrete manner.

In the above considered control options the induction motor start-up takes place practically according to its static performance.

\section{ACKNOWLEDGEMENTS}

The authors are grateful to colleagues of the department of electric drive of KuzGTU for the joint discussion of the problems of dynamic loading of electric drives of mining machinery, as well as valuable comments and recommendations contributing to the improvement of the work.

\section{REFERENCES}

[1] Kovach K., Rats I. Transients in AC machines. - Moscow: State Energy Publisher, 1963. - 744 p.

[2] Kopyilov I.P. Electromechanical energy converters. - Moscow: Energy, 1973. - 400 p.

[3] Grinberg Ya.P. Study of start-up modes of electric motors of coal combines // Coal. 1990. \#5. PP. 33-34

[4] Baskov S.N. The principle of vector-pulse control of AC motors / S.N.Baskov, K.V. Litsin // Bulletin of South Ural State University. 2013 Volume 13, \# 1, pp. 92-94.

[5] A. G. Zhurba. Engines soft start options. Quasi-frequency control. http:// http://epn-plus.ru /index.php?option=com_content\&view=article\&id=129:-q-qq-
$\&$ catid=58:2011-07-17-09-19-11\&Itemid=131

[6] Pereverzev S.S. Start-up control device for non-controlled asynchronous electric drives / S.S. Pereverzev, A.V. Nesterovskiy // Bulletin of KuzSTU. - 2010. - \#5. - pp. 97-100.

[7] Pereverzev S.S. On the issue of formation of mathematical models to study the efficiency of mining and transport machinery start-up control methods / S.S. Pereverzev, A.V. Nesterovskiy // Bulletin of KuzSTU. 2010. - \#6. - pp. 79-85.

[8] Eschin E.K. The problem of the induction motor start-up state control // Bulletin of KuzSTU, 2014. \#3 PP.85-87.

[9] S. Herman, Industrial Motor Control. Delmar, Cengage Learning, 2010 6th Edition, 570 Pages.

[10] Wigington, Adam John, "A Comparison of Induction Motor Starting Methods Being Powered by a Diesel-Generator Set" (2010). Electrical Engineering Theses and Dissertations. Paper 8. 122 Pages. URL: http://digitalcommons.unl.edu/elecengtheses/8 (accessed date 13.01.2016

[11] J. A. Corral-Hernandez, J. Antonino-Daviu, V. Climente-Alarcon, J. Pons-Llinares, and V. Frances-Galiana, "Transient-based rotor cage assessment in induction motors operating with soft-starters," in 2014 International Conference on Optimization of Electrical and Electronic Equipment, OPTIM 2014, 2014, pp. 342-346.

[12] M. Ghadimi, A. Ramezani, and M. Mohammadimehro, "Soft starter modeling for an induction drive starting study in an industrial plant," in Proceedings - UKSim 5th European Modelling Sympo-sium on Computer Modelling and Simulation, EMS 2011, 2011, pp. 245-250.

[13] X. Liang and O. Ilochonwu, "Induction motor starting in practical industrial applications," IEEE Trans. Ind. Appl., vol. 47, no. 1, pp. 271280,2011

[14] J. de Oliveira, A. Nied, M. H. Farias-Santos, and R. Pinho-Dias, "Study on the Energy Effi-ciency of Soft Starting of an Induction Motor with Torque Control," Adv. Mot. Torque Control, vol. 2035, pp. 33-46, 2011.

[15] H.H. Goh, M.S. Looi, and B.C. Kok, Comparison between Direct-OnLine, Star-Delta and Au-to-transformer Induction Motor Starting Method in terms of Power Quality // Proceedings of the International Multi Conference of Engineers and Computer Scientists 2009 Vol II IMECS 2009, March 18 - 20, 2009, Hong Kong.

[16] The mathematical theory of optimal processes / L.S.Pontryagin, V.G Boltyanskiy, R.V.Gamkrelidze, E.F. Mischenko // Moscow: Science, 1983. $392 \mathrm{p}$

[17] Krotov V.F. Methods and problems of optimal control / V.F. Krotov V.I. Gurman // Moscow: Science, 1973. 446 p

[18] A method of starting an induction motor: Patent 2235410 the Russain Federation C1 RU, MПК7 H 02 P 1/26: E.K.Eschin, I.A.Sokolov, V.G.Kashirskih, V.L.Ivanov, D.V.Sokolov; patent applicant and holder is Kuzbass Satete Technical University. -\# 2003100098; Applied 04.01.2003; published 27.08.2004 Bul. \# 24

[19] A method of starting an induction motor: Patent 2572097 the Russain Federation C1 RU, MПК H02P1/26: E.K.Eschin, I.A.Sokolov; paten applicant and holder is "TF. Gorbachev Kuzbass Satete Technical University" (KuzSTU) -\# 2014146972/07; Applied 21.11.2014; published 27.12.2015 Bul. \#36. G. Eason, B. Noble, and I.N. Sneddon, "On certain integrals of Lipschitz-Hankel type involving products of Bessel functions," Phil. Trans. Roy. Soc. London, vol. A247, pp. 529551, April 1955. (references). 